\title{
Co-occurrence of juvenile horseshoe crabs Tachypleus tridentatus and Carcinoscorpius rotundicauda in an estuarine bay, southwestern China
}

\author{
Chang-Po Chen ${ }^{1,2}$, Ming-Che Yang ${ }^{3}$, Lan-Feng Fan ${ }^{3}$, Guanglong Qiu ${ }^{1}$, \\ Yong-Yan Liao ${ }^{4,5}$, Hwey-Lian Hsieh ${ }^{3, *}$ \\ ${ }^{1}$ Guangxi Key Lab of Mangrove Conservation and Utilization, Guangxi Mangrove Research Center, \\ Guangxi Academy of Sciences, Beihai 536000, PR China \\ ${ }^{2}$ Taiwan Wetland Society, Hsinchu 300, Taiwan 115, ROC \\ ${ }^{3}$ Biodiversity Research Center, Academia Sinica, Nankang, Taipei, Taiwan 115, ROC \\ ${ }^{4}$ Ocean School of Qinzhou University, Qinzhou 535000, PR China \\ ${ }^{5}$ Guangxi Key Laboratory of Beibu Gulf Marine Biodiversity Conservation, Qinzhou University, Qinzhou 535000, PR China
}

\begin{abstract}
Spawning and nursery habitats are critical in the conservation of horseshoe crabs. We examined the abundance and distribution of juveniles of 2 species of horseshoe crabs, Tachypleus tridentatus and Carcinoscorpius rotundicauda, in a mangrove-vegetated estuary (Pearl Bay, Guangxi, China). Intertidal sampling and measurement of environmental variables were carried out in October 2014 at 4 sites spanning $~ 6.3 \mathrm{~km}$ from the inner to the outer bay. Both species were found at the 2 innermost mangrove sites but not at the outer 2 sites. Densities were higher than recorded in previous studies, 0.24 ind. $\mathrm{m}^{-2}$ for $C$. rotundicauda and 0.05 ind. $\mathrm{m}^{-2}$ for $T$. tridentatus. Although only 12 of the latter species were found, they appeared to be more abundant in more seaward, energetic environments in poorly sorted sediments, whereas C. rotundicauda occurred in sediments with higher silt-clay and organic carbon content, and aggregated at the mangrove forest edges. These small-scale distribution differences are consonant with the species' life histories, since only $T$. tridentatus migrates to the sea while C. rotundicaudata spends its entire life within or near mangrove habitats. International and national conservation strategies for these species should include further efforts to inventory critical habitats, such as Pearl Bay, in southeast Asia.
\end{abstract}

KEY WORDS: Juvenile horseshoe crab · Distribution - Mangrove · Tidal flat - Estuarine bay · Southern China

\section{INTRODUCTION}

Coastal ecosystems provide essential habitats for many commercially and ecologically valuable fishes and macroinvertebrates, including horseshoe crabs. Beaches, tidal flats, creeks and shallow waters are used by them to fulfil nursery, feeding or reproductive functions (Martin 2014, Seitz et al. 2014). Tachypleus tridentatus once thrived on the coasts of the South and East China Sea but has severely declined

\footnotetext{
${ }^{*}$ Corresponding author: zohl@gate.sinica.edu.tw
}

for decades along the coasts of Japan, Taiwan and China (Itow 1993, Botton 2001, Chen et al. 2004, Hu et al. 2009, Nishida \& Koike 2009, Shin et al. 2009, Yang et al. 2009, Morton \& Lee 2010). Carcinoscropius rotundicauda populations in Hong Kong and Singapore are also threatened and declining (Shin et al. 2009, Cartwright-Taylor et al. 2011, Morton \& Lee 2010). The declines in T. tridentatus are attributed to high demands for Tachypleus amoebocyte lysate, loss of coastal habitats and harvesting for human

() The authors 2015. Open Access under Creative Commons by Attribution Licence. Use, distribution and reproduction are unrestricted. Authors and original publication must be credited. 
consumption. There is a deep concern that these horseshoe crab populations may be decimated if no effective actions are taken to save them, particularly with respect to T. tridentatus (IUCN 2012, P. K. S. Shin unpubl. data). Habitat protection has been considered one of the best strategies to conserve horseshoe crabs (IUCN 2012). Therefore, identification and inventory of critical Asian horseshoe crab habitats at both local and regional scales is a vital first step in these species' conservation (IUCN 2012, P. K. S. Shin unpubl. data), despite the fact that low abundance reported for $T$. tridentatus makes ecological sampling difficult.

Horseshoe crabs requires 3 types of coastal zone habitat to complete its life cycle: adult $T$. tridentatus spawn on open, sandy beaches with coarse sands near the high-tide zone, juveniles forage on adjacent mudflats, and sub-adults and adults continue to grow and mature in deeper subtidal areas (Sekiguchi 1988, Loveland 2001, Chiu \& Morton 2003, Chen et al. 2004, Almendral \& Schoppe 2005, Hsieh \& Chen 2009). In contrast, C. rotundicauda nests at the high-tide level of mangrove-penetrating tidal creeks just beyond the edges of terrestrial land (Cartwright-Taylor \& Hsu 2012). In addition, C. rotundicauda, the so-called mangrove horseshoe crab, is known to spend its life within mangrove swamps or sometimes moves to nearby deeper water but does not migrate to the sea (Davidson et al. 2008, Cartwright-Taylor et al. 2012).

With respect to the habitat availability, mangrovevegetated estuarine bays appear to meet the needs of both $T$. tridentatus and C. rotundicauda. For example, in areas adjacent to the southeastern part of the Pearl River Delta in China, both juvenile T. tridentatus and C. rotundicauda have been recorded to coexist on a few tidal flats along the shallow coasts surrounded by Deep Bay and Lantau Island, Hong Kong (Chiu \& Morton 1999, Shin et al. 2009, Morton \& Lee 2010). In Morton and Lee's (2010) study, juvenile $T$. tridentatus were found to prefer seagrass beds, but there have been no reports of either species' spatial associations with respect to nearby mangroves. The distribution trend observed for juvenile $T$. tridentatus illustrates that they tend to live in seaward rather than landward zones, as the former supports seagrasses while the latter has mangroves.

The coasts of the Beibu Gulf in Guangxi, China, harbor a number of bays which are renowned for their fisheries and shellfisheries, a consequence of the various and numerous habitats they support, including those for horseshoe crabs (Liang 1985, Records of Bays in China 1993, Hu et al. 2009). Liang (1985) reported a nesting beach of $T$. tridentatus on an eastern shore of the Gulf, suggesting that sandy beaches in bays may serve as critical spawning grounds for $T$. tridentatus. Likewise, mangroves in bays are essential for $C$. rotundicauda.

The study area, Pearl Bay, is a mangrove-dominated estuarine ecosystem with patchy seagrass beds and extensive sandy beaches located on the western shore of Beibu Gulf. At low tide, it is common to find adult $C$. rotundicauda in amplexus (male clasping female's opisthosoma) and burying in the mud along the edges of mangrove-penetrating tidal creeks (authors' pers. obs.). However, no T. tridentatus are observed, as mangroves are not suitable spawning sites for $T$. tridentatus.

Based on what is known from the aforementioned literature and observations on the habitat requirements for $T$. tridentatus and C. rotundicauda throughout their life cycle, we predicted that juvenile T. tridentatus would inhabit areas closer to the outer region of the bay and at some distance from the nearest mangroves, whereas juvenile $C$. rotundicauda would tend to use the inner region of the bay and be more closely associated with mangroves. We also predicted that the juveniles of both species would cooccur at some locations within the bay. Pearl Bay appears to be an ideal study site for testing these predictions. The objectives of the present study were to examine the following (1) the spatial distributions of the $T$. tridentatus and C. rotundicauda juvenile populations in Pearl Bay, (2) whether the juveniles of the 2 species co-occured on the same tidal flats, and if so, where these sites were located in the Bay, and (3) the habitat characteristics of the nursery grounds for these 2 horseshoe crab species in relation to environmental variables.

\section{MATERIALS AND METHODS}

\section{Study area}

Pearl Bay is located on the west coast of Beibu Gulf, Guangxi, southwestern China. The bay covers a total area of $94.2 \mathrm{~km}^{2}$, with the coastline stretching for approximately $46 \mathrm{~km}$. The bay opens into Beibu Gulf at its southern end through a relatively narrow and shallow mouth approximately $3.5 \mathrm{~km}$ in width (Fig. 1). Pearl Bay is categorized as a well-mixed bay (Records of Bays in China 1993). The tidal regime of the Bay is characterized as macro-tidal and diurnal, with an average tidal amplitude of $2.24 \mathrm{~m}$ and a maximum amplitude of $5.05 \mathrm{~m}$. Tidal currents flow to the northeast, and near high tide, flow velocities reach a 


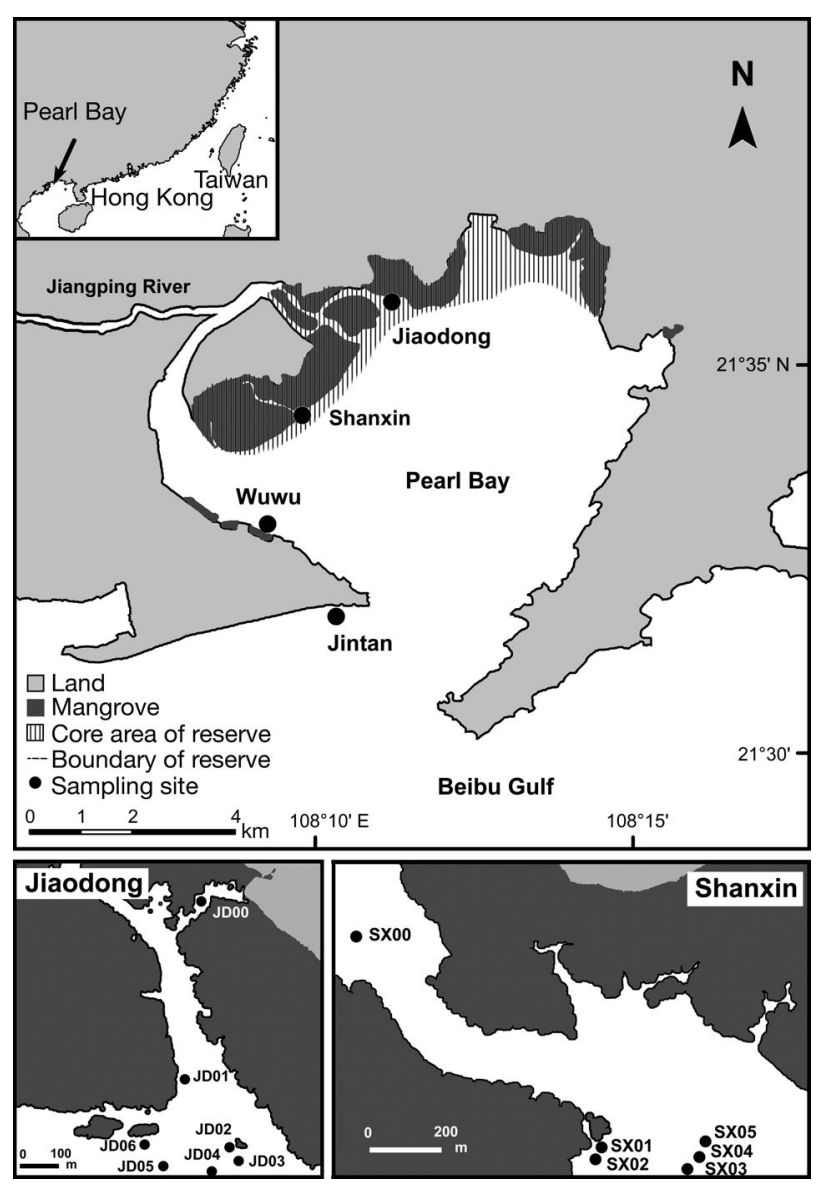

Fig. 1. Study sites at Pearl Bay. Jiaodong and Shanxin are located along the inner bay and have mangrove vegetation, while Wuwu is located in the outer bay and Jintan is located in the coastal zone of the bay. Areas hatched with vertical lines are the planned core areas for mangrove reserves (China Mangrove Conservation Network, www. china-mangrove.org/point/27, accessed on 26 March 2015)

maximum of $48 \mathrm{~cm} \mathrm{~s}^{-1}$ at the bottom of the water column and $55 \mathrm{~cm} \mathrm{~s}^{-1}$ at the surface. Ebb currents flow to the southwest, and near low tide, currents increase, reaching a velocity of $71 \mathrm{~cm} \mathrm{~s}^{-1}$ at the bottom of the water column and $82 \mathrm{~cm} \mathrm{~s}^{-1}$ at the surface. The average wave height reaches $0.52 \mathrm{~m}$ and the maximum wave height is $4.1 \mathrm{~m}$. The bay is shallow, and its bottom consists of tidal creeks and troughs. The water depth ranges from 5 to $10 \mathrm{~m}$ in the trough areas, with the deepest waters measuring $13 \mathrm{~m}$ at the mouth. The northwest and west region of the bay is fed by fresh water from the Jiangping River, which runs through dense mangroves at Jiaodong and Shanxin (Fig. 1). Sand and tidal mudflats in the area are large and generally extend 2 to $3 \mathrm{~km}$ down shore, thus providing habitats for numerous economically important invertebrates, whereas in the southwest region, tidal sand flats are much narrower and stretch approximately 50 to $150 \mathrm{~m}$ down shore.

The mangrove forests in Jiaodong and Shanxin cover approximately 544 ha (Guangxi Mangrove Research Center unpubl. data) and are dominated by Aegiceras corniculatum and Avicennia marina, with some Bruguiera gymnorrhiza and Kandelia obovata. Beds of the seagrass Zostera japonica are distributed seaward and extend from the edges of the mangrove forests on tidal flats, while Halophila beccarii is distributed in small patches on tidal flats, typically along tidal creeks (Qiu et al. 2013, 2014). All mangrovevegetated areas in Pearl Bay are included in the Beilun Estuary Mangrove Nature Reserve (Ma et al. 2011, China Mangrove Conservation Network, www. china-mangrove.org/point/27). Due to the high energy of the tides, waves, winds and the effects of mangrove energy attenuation, the bay is subject to a highly dynamic erosion and sedimentation regime. Annual water temperatures in Pearl Bay average $23.5^{\circ} \mathrm{C}$ and range from a minimum of $9.4^{\circ} \mathrm{C}$ in February to a maximum of $33.6^{\circ} \mathrm{C}$ in July. During the present study period in October, the water temperatures ranged from 22.7 to $31.6^{\circ} \mathrm{C}$ (see Table $\mathrm{S} 1$ in the Supplement at www.int-res.com/articles/suppl/b024 p117_supp.pdf).

\section{Sampling design}

To determine the spatial distributions of juvenile $T$. tridentatus and C. rotundicauda, 4 sites at Pearl Bay were sampled from October 23 to 25, 2014: 2 inner bay (Jiaodong and Shanxin), 1 outer bay (Wuwu) and 1 coastal location (Jintan). All samples were taken during low tides and a total of $296 \mathrm{~m}^{2}$ was sampled (Fig. 1, Table S1). Approximately $3 \mathrm{~h}$ prior to low tide, juveniles are most active and emerge from the substrata (Chen et al. 2004, Morton \& Lee 2010). Emerged juveniles found on the sediment surface and having a size $>1 \mathrm{~cm}$ in carapace length were sampled. Juveniles of the 2 species were distinguishable from adult forms in that they lacked secondary sexual characters (Yamasaki et al. 1988).

Three to 7 sampling stations were set up for each study site. At each station, juvenile abundance was counted and sizes were measured. Environmental variables in the substrata and the shortest distances between the stations and mangrove edges were also measured. Both plot and transect sampling were used to estimate juvenile densities beyond the initial density levels observed in the field. At each station, 
4 plots, each $2 \times 2 \mathrm{~m}$, were haphazardly chosen around a location where horseshoe crabs were found. Where densities at each station were too low to be counted using plot sampling, 2 transect lines, each $20 \mathrm{~m}$ long and $1 \mathrm{~m}$ wide, were used. In addition, 3 transects of the same size were set up parallel to the mangrove forest edge $15 \mathrm{~m}$ apart at Stn JD01 of the Jiaodong site with a total sampling area of $60 \mathrm{~m}^{2}$.

\section{Measurement of body size, estimation of juvenile horseshoe crab density and spatial relation with the mangrove}

At all plots $\left(16 \mathrm{~m}^{2}\right.$ in total) and transects (either 40 or $60 \mathrm{~m}^{2}$ ) at each station, juvenile horseshoe crabs were collected, identified to species level, counted to establish abundance, and measured with a digital caliper to determine each crab's maximum prosomal width (Absolute ${ }^{\mathrm{TM}}$, Mitutoyo $\left.{ }^{(}\right)$. The numbers of spines growing along the central ridge on the dorsum of the opisthosomal carapace were used to distinguish between the 2 species. There are 3 spines on T. tridentatus whereas $C$. rotundicauda has only 2 spines.

For each species, the spatial relationship between juvenile size and distance to the nearest mangrove was analyzed by plotting a size-frequency distribution of prosomal widths against the distance to the nearest mangrove. When appropriate, the density and the width were expressed as mean $\pm \mathrm{SE}$ ind. $\mathrm{m}^{-2}$ and mean $\pm \mathrm{SE} \mathrm{mm}$, respectively.

\section{Measurement of environmental variables}

A total of 12 environmental variables were measured (Table S1 in the Supplement). Collections and analyses of sediment variables followed the procedures described in Hsu et al. (2009). Sediments were collected using an acrylic tube with $2.6 \mathrm{~cm}$ diameter. During transport to the laboratory, all sediment samples were kept cool at $\sim 4{ }^{\circ} \mathrm{C}$, while those for chlorophyll a (chl a) content measurement were also kept in the dark. The top $3 \mathrm{~cm}$ of the sediment were sampled and analyzed for granulometry, $\mathrm{pH}$, salinity, total organic carbon (TOC) and total nitrogen (TN) contents, and chl a samples were taken from the top $0.5 \mathrm{~cm}$. In the laboratory, samples for measurement of TOC, TN and chl a content were kept at $-80^{\circ} \mathrm{C}$ until cryo-dried. Granulometry (including grain size, silt and clay content and degree of sorting) was determined following a protocol developed by Hsieh \& Chang (1991). Sediment pH values were measured using a glass electrode $\mathrm{pH}$ meter in a 1:2 ratio of sediment to deionized water by weight. Sediment salinity was determined using a refractometer on the strained interstitial water after the sediment was centrifuged. Sediment TOC and TN contents were analyzed using an element analyzer (Perkin-Elmer 2400 Series II CHNS/O analyzer) after sediments were treated by cryo-drying, passed through a $0.5 \mathrm{~mm}$ sieve to remove large animal pieces and plant debris, acidified with $1 \mathrm{~N} \mathrm{HCl}$ to remove inorganic carbons, and ground to a fine powder. Chl a was extracted with $90 \%$ acetone and analyzed using a fluorescence spectrophotometer (Eclipse GMJL006, Varian) and concentrations were expressed as $\mu \mathrm{g} \mathrm{cm}^{-2}$. In addition, the shortest distances between the stations and the mangrove edges (DisM) were determined using Google Earth based on the geographic coordinates recorded for each station during field sampling.

\section{Statistical analysis}

Spearman correlations were used to analyze the relationship between juvenile densities of $T$. tridentatus and C. rotundicauda and DisM. The correlation statistics were based on the data from 7 stations at the 2 inner sites, Jiaodong (JD01, JD05-06) and Shanxin (SX01-04), and performed using SAS 9.1 software (SAS Institute 2003). Multivariate ordination techniques were used to examine additional relationships between the juvenile densities for each species and other environmental variables. Two biotic variables, measured as the densities of the 2 species, and 12 environmental variables collected from all 4 sites were included in the analysis. The juvenile densities and environmental variables were log transformed before analysis. A prior de-trended correspondence analysis (DCA) of horseshoe crab density was conducted separately to assess the gradient length of the first DCA axis. The length of the gradient was 1.414 (in SD units). Based on this information, a linear model, also known as a redundancy analysis (RDA), was chosen for our data set (ter Braak $\&$ Šmilauer 2012). We utilized the automatic forwardselection mode in our analysis and only included environmental variables that explained a significant proportion of the remaining variation (based on a Monte Carlo test with 999 permutations at $\mathrm{p} \leq$ 0.1). An ordination analysis was performed using CANOCO for Windows v.5.0 (ter Braak \& Šmilauer 2012). 


\section{RESULTS}

\section{Spatial distribution of juvenile horseshoe crabs}

A total of 65 juvenile horseshoe crabs were recorded throughout this study, consisting of 12 Tachypleus tridentatus and 53 Carcinoscorpius rotundicauda. Spatial distribution patterns were revealed across 3 scales: large, intermediate and micro. At the largest spatial scale, which includes all 4 sampling sites, juvenile $T$. tridentatus and C. rotundicauda cooccurred at the 2 inner sites (Jiaodong and Shanxin) within the bay, while none were found at the outer site (Wuwu) or the site beyond the bay (Jintan) (Table 1, Fig. S1 in the Supplement at www.int-res. com/articles/suppl/b024p117_supp.pdf). At the 2 inner sites, C. rotundicauda exhibited higher densities than $T$. tridentatus $(0.24 \pm 0.05$ vs. $0.05 \pm 0.03$ ind. $\mathrm{m}^{-2}$ ). In addition, $T$. tridentatus was found in lower densities at Jiaodong than at Shanxin $(0.02 \pm 0.02$ vs. $0.11 \pm 0.07$ ind. $\mathrm{m}^{-2}$ ), while C. rotundicauda had similar densities at both inner sites $\left(0.25 \pm 0.02\right.$ ind. $\mathrm{m}^{-2}$ at Jiaodong and $0.22 \pm 0.04$ ind. $\mathrm{m}^{-2}$ at Shanxin, Fig. S1).

At the intermediate (among stations between sites) and micro spatial scales (among stations within a site), the densities of $T$. tridentatus and C. rotundicauda revealed different trends in the species' relative proximities to mangroves and tidal flats. Densities juvenile $T$. tridentatus increased from the

Table 1. Juvenile densities of Tachypleus tridentatus and Carcinoscorpius rodunticauda at different spatial scales in Pearl Bay, China. Sampling took place at low tides in October 2014. Additional stations were also monitored, but only those stations that served for density comparisons at intermediate and micro spatial scales are given in this table. See Table S1 in the Supplement at www.int-res.com/articles/ suppl/b024p117_supp.pdf for detailed sampling information. DisM: distance to the nearest mangrove

\begin{tabular}{|c|c|c|c|c|c|}
\hline \multirow[t]{2}{*}{ Spatial scale } & \multirow[t]{2}{*}{ Site } & \multirow[t]{2}{*}{ Stn } & \multirow{2}{*}{$\begin{array}{c}\text { DisM } \\
(\mathrm{m})\end{array}$} & \multicolumn{2}{|c|}{ - Density (ind. $\mathrm{m}^{-2}$ ) } \\
\hline & & & & T. tridentatus & C. rotundicauda \\
\hline \multirow{4}{*}{$\begin{array}{l}\text { Largest } \\
\text { (from inner } \\
\text { bay to coastal } \\
\text { zone) }\end{array}$} & Jiaodong & & & $0.02 \pm 0.02$ & $0.25 \pm 0.02$ \\
\hline & Shanxin & & & $0.11 \pm 0.07$ & $0.22 \pm 0.04$ \\
\hline & Wuwu & & & 0 & 0 \\
\hline & Jintan & & & 0 & 0 \\
\hline \multirow{7}{*}{$\begin{array}{l}\text { Intermediate } \\
\text { (among stations } \\
\text { between sites) }\end{array}$} & Jiaodong & JD01 & 30.2 & 0 & 0.40 \\
\hline & & JD06 & 46.1 & 0.05 & 0.25 \\
\hline & & JD05 & 187.8 & 0.10 & 0.23 \\
\hline & Shanxin & SX01 & 1.6 & 0 & 0.31 \\
\hline & & SX02 & 22.8 & 0.06 & 0.25 \\
\hline & & SX04 & 275.3 & 0.19 & 0.13 \\
\hline & & SX03 & 233.0 & 0.38 & 0.13 \\
\hline \multirow{3}{*}{$\begin{array}{l}\text { Micro (among } \\
\text { stations within } \\
\text { a site) }\end{array}$} & Jiaodong & $\mathrm{T} 1$ & 15.0 & 0 & 0.65 \\
\hline & $(\mathrm{JD01})$ & $\mathrm{T} 2$ & 30.0 & 0 & 0.15 \\
\hline & & T3 & 45.0 & 0 & 0 \\
\hline
\end{tabular}

locations close to the mangrove edges to the locations on the open, non-vegetated tidal flats, but those of C. rotundicauda decreased along the same spatial gradient (Table 1; from JD01 through JD06 to JD05 in Fig. S2 in the Supplement and from SX01 through SX02, SX04 to SX03 in Fig. S3 in the Supplement). For $C$. rotundicauda, the same distribution trend along the mangrove-tidal flat gradient was found at an even smaller scale. Among transects at Stn JD01, the spatial range of $C$. rotundicauda stretched across 3 parallel transects, each $15 \mathrm{~m}$ apart. Across these transects, the densities of $C$. rotundicauda decreased sharply from the mangrove edge to the tidal flat $\left(0.65,0.15\right.$ and 0 ind. $\mathrm{m}^{-2}$, respectively, Table 1 ; Fig. S4 in the Supplement).

Tachypleus tridentatus densities were significantly and positively correlated with distance from the nearest mangroves, while the correlation of $C$. rotundicauda densities was significantly negative (Spearman $\mathrm{r}=0.83, \mathrm{p}=0.02$ vs. $\mathrm{r}=-0.86, \mathrm{p}=0.01, \mathrm{n}=7$, Fig. 2).

\section{Relationship between juvenile body size and proximity to the nearest mangrove}

The juveniles of the 2 horseshoe crab species measured between 15 and $65 \mathrm{~mm}$ in prosomal width (Table S2 in the Supplement at www.int-res.com/ articles/suppl/b024p117_supp.pdf). The majority of juvenile $T$. tridentatus had a prosomal width between 25 and $45 \mathrm{~mm}$, whereas most of the juvenile C. rotundicauda had a prosomal width between 30 and $40 \mathrm{~mm}$ (Table S2). The prosomal width of $T$. tridentatus averaged $36.2 \pm$ $11.4 \mathrm{~mm}$ at Jiaodong and $35.9 \pm$ $2.7 \mathrm{~mm}$ at Shanxin, while that of C. rotundicauda averaged $31.7 \pm$ $2.1 \mathrm{~mm}$ at Jiaodong and $34.7 \pm$ $1.5 \mathrm{~mm}$ at Shanxin, showing that the juvenile sizes of both species were similar, with $T$. tridentatus being slightly larger.

The size distribution profiles, plotted against the distance to the nearest mangrove edge, varied between species. The smaller juveniles of $C$. rotundicauda tended to aggregate in closer proximity to the mangrove forest edges than did the larger individuals (Fig. 3). Small individuals of 15 to $45 \mathrm{~mm}$ 


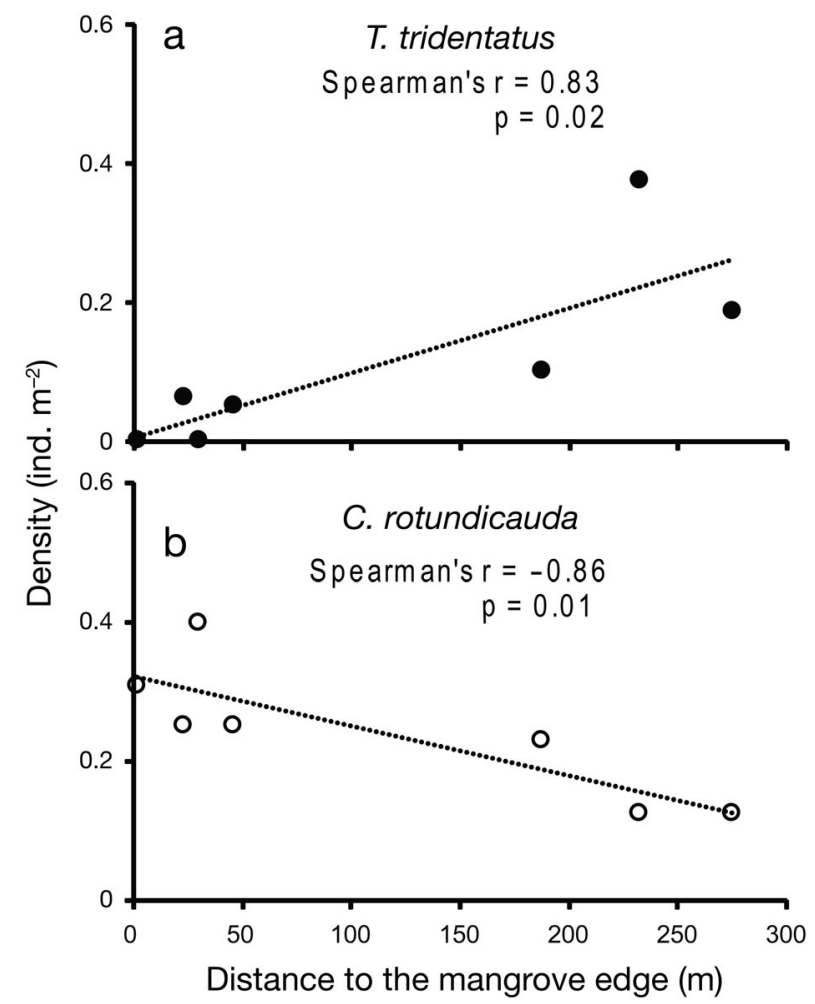

Fig. 2. Spearman correlation analyses showing the relationships of density and the distance to the nearest mangrove in juvenile (a) Tachypleus tridentatus and (b) Carcinoscorpius rotundicauda. Data points were from Stns JD01, JD05-06, and SX01-04. Dashed lines show correlation trends

prosomal width $-75 \%$ of the crabs observed - were distributed within $\sim 50 \mathrm{~m}$ of a mangrove edge, while large individuals of 30 to $65 \mathrm{~mm}$ - the remaining $25 \%$ of the crabs - were distributed 188 to $275 \mathrm{~m}$ away from the mangrove edge (Fig. 3, Table S2). In contrast, no trend was evident for T. tridentatus size classes (Fig. 3).

\section{Relationships of juvenile densities with environmental variables}

The redundancy analysis with automatic forward selection showed that the juvenile densities of $T$. tridentatus and C. rotundicauda were significantly correlated with the studied environmental variables, including TOC content, silt-clay content, degree of sorting, chl a concentration and DisM (all p values $\leq$ 0.1, Monte Carlo permutation with 999 permutations, Table 2). These 5 environmental variables explained $68 \%$ of the total variation in juvenile densities of both species $(F=5.9, \mathrm{p}=0.002$, Monte Carlo permutation test with 999 permutations, Table 3).

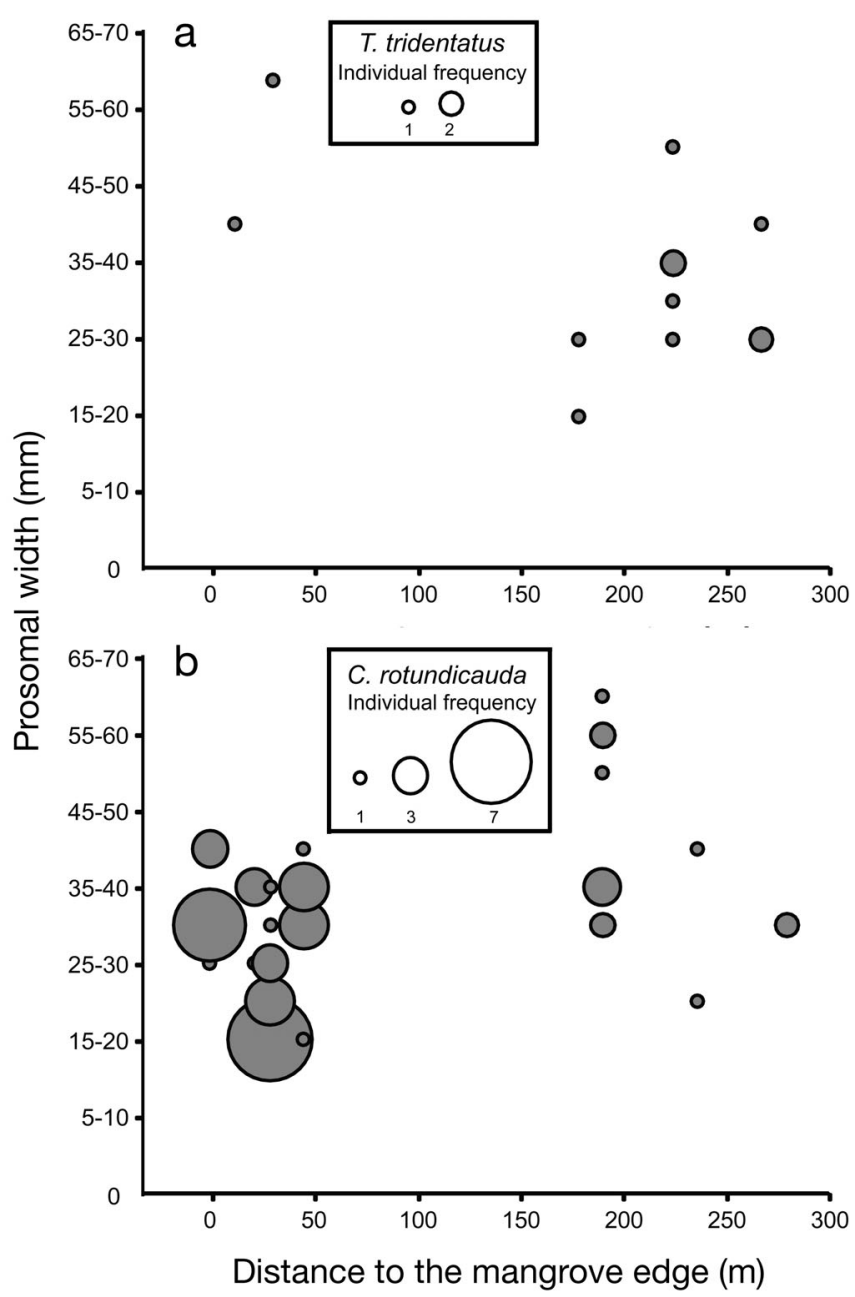

Fig. 3. Spatial relationships between different body sizes (prosomal width) and the distance to the nearest mangrove for juvenile (a) Tachypleus tridentatus and (b) Carcinoscorpius rotundicauda using the data combined from the Jiaodong and Shanxin sites

Table 2. Redundancy analysis results showing the environment variables that significantly (Monte Carlo permutation tests, $\mathrm{p} \leq 0.1$ ) explained changes in the density of juvenile horseshoe crabs Tachypleus tridentatus and Carcinoscorpius rotundicauda in Pearl Bay. Environmental variables that best explain these density changes are ranked first, while the remaining variables are ranked on the basis of the additional fit from the model selection. TOC: total organic carbon content; DisM: distance to the nearest mangrove

\begin{tabular}{|lcccrrr|}
\hline Selected variables & $F$ & $\mathrm{p}$ & $\begin{array}{r}\text { Variance } \\
\text { explained }\end{array}$ & \multicolumn{2}{c|}{$\begin{array}{c}\text { Correlation } \\
\text { Axis 1 }\end{array}$} & Axis 2 \\
& & & & & & \\
TOC & 10.3 & 0.002 & 0.37 & 0.72 & -0.02 \\
Silt-clay content & 4.3 & 0.01 & 0.13 & 0.72 & -0.23 \\
Sorting coefficient & 2.4 & 0.09 & 0.07 & 0.46 & -0.37 \\
Chl a & 2.8 & 0.06 & 0.06 & -0.24 & -0.11 \\
DisM & 2.2 & 0.1 & 0.06 & -0.35 & -0.01 \\
& & & & & & \\
\hline
\end{tabular}


Table 3. Summary of the statistics from the redundancy analysis of the relationships between environmental variables and the juvenile densities of the horseshoe crabs Tachypleus tridentatus and Carcinoscorpius rotundicauda in Pearl Bay

\begin{tabular}{|c|c|c|c|c|c|c|}
\hline & \multicolumn{4}{|c|}{ Ordination axis } & \multirow{2}{*}{$\begin{array}{c}\text { Total } \\
\text { variance } \\
1.00\end{array}$} & Full model \\
\hline & 1 & 2 & 3 & 4 & & $F \quad \mathrm{p}$ \\
\hline Eigenvalue & 0.52 & 0.16 & 0.20 & 0.12 & & $5.9 \quad 0.002$ \\
\hline Species-environment correlation & 0.85 & 0.75 & 0 & 0 & & \\
\hline $\begin{array}{l}\text { Cumulative } \% \text { variance explained } \\
\text { by species data } \\
\text { by species-environment correlation }\end{array}$ & $\begin{array}{l}52.1 \\
76.4\end{array}$ & $\begin{array}{c}68.1 \\
100.0\end{array}$ & $\begin{array}{c}87.6 \\
0\end{array}$ & $\begin{array}{c}100.0 \\
0\end{array}$ & & \\
\hline Sum of all canonical eigenvalues & & & & & 0.68 & \\
\hline
\end{tabular}

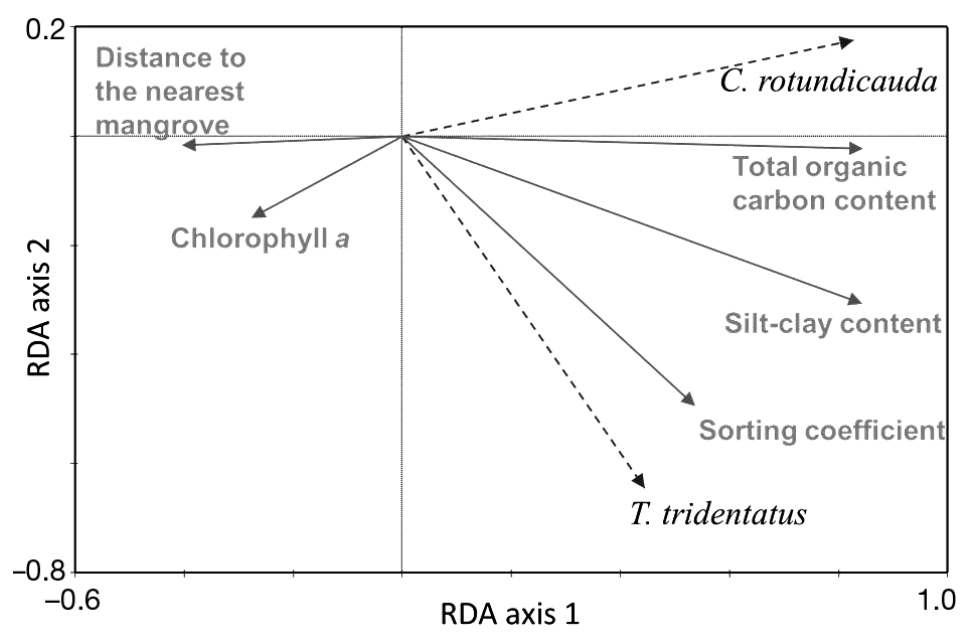

Fig. 4. Redundancy analysis (RDA) showing the ordination diagram of juvenile densities for Tachypleus tridentatus and Carcinoscorpius rotundicauda (dashed arrows) with environmental variables (solid arrows)

The redundancy analysis results showed that the relationship between juvenile density and each of the 5 environmental variables varied with species. The density of juvenile $T$. tridentatus increased with decreasing degree of sediment sorting, whereas juvenile $C$. rotundicauda densities exhibited greater positive relationships to TOC content and silt-clay content (Fig. 4). Although DisM and chl a concentra- tions in the sampled sediments explained the juvenile density changes to a lesser extent (variances explained), the densities of both species were negatively correlated with these 2 factors. Moreover, $C$. rotundicauda remained closer to the mangroves than $T$. tridentatus (ordinations on RDA axis 2, Fig. 4). The average DisM for C. rotundicauda was $113.8 \mathrm{~m}$, while that for $T$. tridentatus was $153 \mathrm{~m}$ (calculated from Table 1 data).

\section{DISCUSSION}

In the present study, only 12 Tachypleus tridentatus juveniles were collected, thus the findings need to be interpreted with caution. However, this low number does highlight that this species is becoming rare and deserves urgent protection and conservation.

The juvenile densities of $T$. tridentatus and $C$. rotundicauda at Pearl Bay are among the highest in comparison to those at other sites (Table 4), revealing that Pearl Bay in southwestern China is a critical habitat for the 2 horseshoe crab species. In particular, the densities of $T$. tridentatus were 25- to 37-fold higher (Table 4). In Pearl Bay, the spatial distribution of juveniles varies according to species, body size, proximity to the mouth of the bay, proximity to mangrove vegetation, and microhabitats. Our findings may facilitate the habitat conservation of the 2 horseshoe crab species and other co-existing commercial species. In particular, such coastal habitats have been considered endangered due to anthropogenic impacts (Martin 2014).

Table 4. Comparisons of juvenile densities of Tachypleus tridentatus and Carcinoscorpius rotundicauda among different areas. -: no record

\begin{tabular}{|lccl|}
\hline Area & $\begin{array}{c}\text { T. tridentatus } \\
\text { (ind. } \mathrm{m}^{-2} \text { ) }(\text { range })\end{array}$ & $\begin{array}{c}\text { C. rotundicauda } \\
\text { (ind. } \mathrm{m}^{-2} \text { ) }\end{array}$ & Reference \\
\hline Puerto Bay, Philippines & $0.0075-0.015$ & - & Almendral \& Schoppe (2005) \\
Silver Bay, East Beibu Gulf, Guangxi, China & $0.0009-0.024$ & - & Hu et al. (2009) \\
Deep Bay and Lantau Island, Hong Kong & $0.0008-0.003$ & Almost zero & $\begin{array}{l}\text { Shin et al. (2009) } \\
\text { Deep Bay, Hong Kong }\end{array}$ \\
Pearl Bay, West Beibu Gulf, Guangxi, China & $0.011-0.02$ & Almost zero & Morton \& Lee (2010) \\
\hline
\end{tabular}


The co-occurrence of juvenile $T$. tridentatus and $C$. rotundicauda at the Jiaodong and Shanxin sites in the inner zones of Pearl Bay is consistent with our prediction and can be explained by the specific habitat requirements necessitated by the unique life history of each species. In general, the life histories of T. tridentatus and C. rotundicauda have been well documented (Sekiguchi 1988, Chen et al. 2004, Cartwright-Taylor et al. 2009, 2012, Cartwright-Taylor \& Hsu 2012). These records reveal that the 2 species differ in their demands for spawning and maturation sites, but utilize the same kind of mud and/or mud-sand flats as juvenile nursery grounds.

Pearl Bay is a predominantly mangrove-vegetated estuarine bay. Its inner sections support dense mangroves, which spread along the estuary of Jiangping River. Its outer reaches connect to the sea (Beibu Gulf) and are characterized by open, sandy shores (Records of Bays in China 1993). With this bio- and geomorphological setting, the Bay has the potential to serve as an important migratory path for departing $T$. tridentatus subadults seeking to reach maturation sites in deeper channels ( 20 to $30 \mathrm{~m}$ depth, Liang 1985, Hsieh \& Chen 2015) along the coasts of the Bay and for returning adults who need to access nesting sites on the bay's sandy beaches. The bay also provides suitable habitat in the form of mangrove swamps to allow $C$. rotundicauda to complete its life cycle.

Most significantly, the bay, with its large intertidal sand and mud flats, provides nourishment for the juveniles of the 2 horseshoe crab species. Analysis of sediment characteristics reveal that the inner bay experiences deposition while the outer and coastal areas are subject to erosion. In addition, prior measurements revealed that during flood tides, the prevalent flow direction was to the northeast with a high velocity, while at ebb tides, the flow direction shifted to the southwest and had an even higher velocity (Records of Bays in China 1993). Given such a flow regime, we reason that the first instars of $T$. tridentatus hatch from their nests when high tides wash the sandy beaches and are very likely to be conveyed by the northeastern currents toward the inner Bay to settle in areas subject to deposition. Those areas also happen to be ideal habitat for mangroves and the mangrove horseshoe crab $C$. rotundicauda.

The distinct spatial associations between juvenile size and the DisM for each species can be attributed to the differences in spawning sites and the separation between adult spawning and juvenile nursery sites. C. rotundicauda nests on tidal creeks within mangroves; therefore, the hatchlings are able to easily transfer to the adjacent mudflats within the mangroves (Cartwright-Taylor \& Hsu 2012). Consequently, smaller juveniles appear to aggregate in a close proximity to mangroves. In contrast, the spawning sites of $T$. tridentatus are not located in the mangroves but on sandy beaches as seen at Beihai coast, Guangxi (Liang 1985), Hakata Bay, Japan (Sekiguchi 1988) and Kinmen, Taiwan (Chen et al. 2004). Sand bars are well developed in the outer regions of the bay, which include the study sites Wuwu and Jintan (Records of Bays in China 1993). In addition, some outer edges of the sand flats at the Jiaodong and Shanxin sites are slightly more elevated than the adjacent tidal flats (authors' personal observation). These sandy beaches very likely serve as nesting sites for $T$. tridentatus and are separated from the mangroves; consequently, the localities that juvenile T. tridentatus inhabit do not necessarily occur in close proximity to the mangroves.

Our data reveal that juvenile $T$. tridentatus can explore more habitat types than juvenile $C$. rotundicauda. Juvenile $T$. tridentatus are distributed on intertidal fine sand flats in mangrove- and seagrassvegetated estuarine bays or coasts (such as Pearl Bay of this study and Silver Bay coast studied by Hu et al. 2009), differing from those also found in open, nonmangrove vegetated headland bays (such as bays studied by Chen et al. 2004, Hsieh \& Chen 2009 and Weng et al. 2012). In contrast, C. rotundicauda has been recorded persistently within or near mangrove habitats (this study, Cartwright-Taylor \& Hsu 2012, Cartwright-Taylor et al. 2012), reflecting its habitat specificity.

The juveniles of both $T$. tridentatus and $C$. rotundicauda exhibit a preference for localities with poorly sorted sediments that have high organic carbon content. These physico-chemical properties of sediments suggest that various forms of food are available there. Organic matter buried in sediments is found to benefit many detritivores and through conversion and transfer contributes to the sustenance of many consumers at higher trophic levels within mangrove ecosystems (Hsieh et al. 2002). With respect to food sources for juvenile $T$. tridentatus and $C$. rotundicauda, the data from $\delta^{13} \mathrm{C}$ signatures showed that seagrass-derived organic matter, rather than that of mangroves, was assimilated by the juveniles of both T. tridentatus and C. rotundicauda in Pearl Bay (authors' unpubl. data). A mix of polychaetes, bivalves and gastropods that are supported by seagrass biomass comprised the diet of juvenile T. tridentatus studied in Hong Kong (Kwan et al. 2015). Benthic microalgae were also found to contribute to the diet of C. rotundicauda studied in Malaysia (Newell et al. 
1995). Benthic microalgae primarily grow on open sandy tidal flats and are rarely found on mud flats or under the canopy of mangroves (Wainright et al. 2000, Hsieh et al. 2002). Given these food sources and their locations, the critical nursery grounds of $T$. tridentatus and $C$. rotundicauda should consist of a variety of habitats, including open sandy and muddy tidal flats, seagrass beds and mangroves.

We recommend the following strategic guidelines for horseshoe crab conservation. (1) Identify critical habitats for horseshoe crabs. Nesting beaches and migratory routes for $T$. tridentatus and nesting tidal creeks for $C$. rotundicauda are key habitats. It is essential to inventory and identify these habitats on the southern coast of China. (2) Increase legal protection of critical habitats. In bays, harvest activities that adversely affect habitats include rearing free-range ducks in mangroves, bottom trawling and collecting clams with rakes. These activities should be monitored and managed. Alternatively, the conservation of critical habitats can be incorporated into current laws mandating mangrove protection. Recently, the IUCN Species Survival Commission for horseshoe crabs has launched protection programs to put these species on the IUCN Red List. (3) Raise public awareness of horseshoe crab conservation efforts. Education programs could include (i) advising local fishermen to cease with bottom trawling and to avoid deploying fishing nets and cages in mangrove protected areas, (ii) advising the public not to consume ducks reared in mangroves, (iii) empowering local non-government organizations to monitor the stressors of horseshoe crab habitats and populations, and (iv) making the public aware of the use Tachypleus amoebocyte lysate for medicinal puposes.

Acknowledgements. The authors thank the anonymous reviewers who greatly improved this manuscript. The authors are grateful to Yongze Xing, Zhinan Su, Mingliu Yang and Lingyu Huang for their field and laboratory support. This research was supported by the Open Research Fund of Guangxi Key Laboratory of Mangrove Conservation and Utilization under GKLMC-201304 and National Natural Science Foundation of China under 41466003. The study fully complies with the current laws of China regarding research ethics and animal welfare.

\section{LITERATURE CITED}

Almendral MA, Schoppe S (2005) Population structure of Tachypleus tridentatus (Chelicerata: Merostomata) at a nursery beach in Puerto Princesa City, Palawan, Philippines. J Nat Hist 39:2319-2329

Botton ML (2001) The conservation of horseshoe crabs: What can we learn from the Japanese experience? In:
Tanacredi JT (ed) Limulus in the limelight. Kluwer Academic/Plenum, New York, NY, p 41-51

- Cartwright-Taylor L, Hsu CC (2012) Follow-up study on population structure and breeding pattern of the mangrove horseshoe crab Carcinoscorpius rotundicauda in Singapore. Aquat Biol 14:217-222

> Cartwright-Taylor L, Lee J, Hsu CC (2009) Population structure and breeding pattern of the mangrove horseshoe crab Carcinoscorpius rotundicauda in Singapore. Aquat Biol 8:61-69

Cartwright-Taylor L, Bing YV, Hsu CC, Lou ST (2011) Distribution and abundance of horseshoe crabs Tachypleus gigas and Carcinoscorpius rotundicauda around the main island of Singapore. Aquat Biol 13:127-136

Cartwright-Taylor L, Ng HH, Goh TY (2012) Tracked mangrove horseshoe crab Carcinoscorpius rotundicauda remain resident in a tropical estuary. Aquat Biol 17: 235-245

Chen CP, Yeh HY, Lin PF (2004) Conservation of the horseshoe crab at Kinmen, Taiwan: strategies and practices. Biodivers Conserv 13:1889-1904

Chiu HMC, Morton B (1999) The distribution of horseshoe crabs (Tachypleus tridentatus and Carcinoscorpius rotundicauda) in Hong Kong. Asian Mar Biol 16:185-196

Chiu HMC, Morton B (2003) The sediment and hydrographic characteristics of three horseshoe crab nursery beaches in Hong Kong. J Ocean Univ Qingdao 2:35-43

Davidson GWH, Ng PKL, Ho HC (2008) The Singapore Red Data Book: threatened plants and animals of Singapore. The Nature Society (Singapore), Singapore

Hsieh HL, Chang KH (1991) Habitat characteristics and occurrence of the spionid Pseodupolydora sp. on the tubecaps of the onuphid Diopatra biolobata (Polychaeta: Spionidae, Onuphidae). Bull Inst Zool Acad Sin 30: 331-339

Hsieh HL, Chen CP (2009) Conservation program for the Asian horseshoe crab Tachypleus tridentatus in Taiwan: characterizing the microhabitat of nursery grounds and restoring spawning grounds. In: Tanacredi JT, Botton ML, Smith DR (eds) The biology and conservation of horseshoe crabs. Springer, New York, NY, p 417-438

Hsieh HL, Chen CP (2015) Current status of Tachypleus tridentatus in Taiwan for Red List assessment. In: Carmichael RH, Botton ML, Shin PKS, Cheung SG (eds) Changing global perspectives on biology, conservation, and management of horseshoe crabs. Springer, New York, NY, p 383-396

> Hsieh HL, Chen CP, Chen YG, Yang HH (2002) Diversity of benthic organic matter flows through polychaetes and crabs in a mangrove estuary: $\delta^{13} \mathrm{C}$ and $\delta^{34} \mathrm{~S}$ signals. Mar Ecol Prog Ser 227:145-155

- Hsu CB, Chen CP, Hsieh HL (2009) Effects of sediment compaction on macroinfauna in a protected coastal wetland in Taiwan. Mar Ecol Prog Ser 375:73-83

> Hu M, Wang Y, Chen Y, Cheung SG, Shin PKS, Li Q (2009) Summer distribution and abundance of juvenile Chinese horseshoe crabs Tachypleus tridentatus along an intertidal zone in southern China. Aquat Biol 7:107-112

Itow T (1993) Crisis in the Seto Inland Sea: the decimation of the horseshoe crab. EMECS Newslett 3:10-11

IUCN (2012) M034 The conservation of Asian horseshoe crabs. https://portals.iucn.org/docs/2012congress/motions/es/M034-2012-SP.pdf (accessed 11 June 2014)

Kwan BKY, Cheung SG, Shin PKS (2015) A dual stable isotope study for diet composition of juvenile Chinese horse- 
shoe crab Tachypleus tridentatus (Xiphosura) on a seagrass-covered intertial mudflat. Mar Biol 162:1137-1143

Liang GY (1985) Preliminary survey on the horseshoe crab resources in Beibu Gulf. Guangxi Agric Sci 2:18-20 (in Chinese)

Loveland RE (2001) The life history of horseshoe crabs. In: Tanacredi JT (ed) Limulus in the limelight. Kluwer Academic/Plenum, New York, NY, p 93-101

Ma YJ, Su B, Meng ZJ (2011) Autum and winter survey of waterbirds in national natural reserve of Beilun Estuary of Guangxi. Guangxi Sci 18:73-78 (in Chinese with English Abstract)

Martin KLM (2014) Beach-spawning fishes: Reproduction in an endangered ecosystem. CRC Press, Taylor \& Francis, New York, NY

Morton B, Lee CN (2010) Spatial and temporal distributions of juvenile horseshoe crabs (Arthropoda: Chelicerata) approaching extirpation along the northwestern shoreline of the New Territories of Hong Kong SAR, China. J Nat Hist 45:227-251

Newell RIE, Marshall N, Sasekumar A, Chong VC (1995) Relative importance of benthic microalgae, phytoplankton, and mangroves as sources of nutrition for penaeid prawns and other coastal invertebrates from Malaysia. Mar Biol 123:595-606

Nishida S, Koike H (2009) Genetic structure of Japanese populations of Tachypleus tridentatus by mtDNA ATrich region sequence analysis. In: Tanacredi JT, Botton ML, Smith DR (eds) The biology and conservation of horseshoe crabs. Springer, New York, NY, p 183-196

Qiu GL, Fan HQ, Li ZS, Liu GH, Shi YJ, Li S (2013) Population dynamics and seed banks of the threatened seagrass Halophila beccarii in Pearl Bay, Guangxi. Acta Ecol Sin 33:6163-6172 (in Chinese with English Abstract)

Qiu GL, Fan HQ, Li LX, Li S (2014) Restorations of the intertidal seagrass beds. China Forestry Publishing House, Beijing, p 31-34 (in Chinese)

Records of Bays in China (1993). Bays in Guangxi. In:

Editorial responsibility: Judith Grassle,

New Brunswick, New Jersey, USA
China Bay Editing Commission (ed) Records of Bays in China, Vol 12. China Ocean Press, Beijing, p 268-313 (in Chinese)

SAS Institute (2003). SAS user's guide: statistics, release 9.1. SAS Institute, Cary, NC

Seitz RD, Wennhage H, Bergstrom U, Lipcius RN, Ysebaert $\mathrm{T}$ (2014) Ecological value of coastal habitats for commercially and ecologically important species. ICES J Mar Sci 71:648-665

Sekiguchi K (1988) Ecology. In: Sekiguchi K (ed) Biology of horseshoe crabs. Science House, Tokyo, p 50-68

Shin PKS, Li HY, Cheung SG (2009) Horseshoe crabs in Hong Kong: current population status and human exploitation. In: Tanacredi JT, Botton ML, Smith DR (eds) The biology and conservation of horseshoe crabs. Springer, New York, NY, p 347-360

ter Braak CJF, Šmilauer P (2012) Canoco reference manual and user's guide: software for ordination (Version 5.0). Microcomputer Power, Ithaca, NY

$>$ Wainright SC, Weinstein MP, Able KW, Currin CA (2000) Relative importance of benthic microalgae, phytoplankton and the detritus of smooth cordgrass Spartina alterniflora and the common reed Phragmites australis to brackis-marsh food webs. Mar Ecol Prog Ser 200:77-91

Weng ZH, Xie YJ, Xiao ZQ, Huang LM, Li J, Wang SH, Zhang YZ (2012) Distribution and resource of Chinese horseshoe crab (Tachypleus tridentatus) in Fujian and other coast water of China. Chinese J Zool 47:40-48 (in Chinese with English Abstract)

Yamasaki T, Makioka T, Saito j (1988) Morphology. In: Sekiguchi K (ed) Biology of horseshoe crabs. Science House, Tokyo, p 69-104

Yang MC, Chen CP, Hsieh HL, Huang H, Chen CA (2009) Phylogeography, demographic history, and reserves network of horseshoe crab, Tachypleus tridentatus, in the south and east China Seaboards. In: Tanacredi JT, Botton ML, Smith DR (eds) The biology and conservation of horseshoe crabs. Springer, New York, NY, p 163-181

Submitted: July 15, 2015; Accepted: October 15, 2015

Proofs received from author(s): November 19, 2015 